\title{
ESTIMATION OF BIOCHEMICAL CONSTITUENTS FROM FRESH, GREEN LEAVES BY SPECTRUM MATCHING TECHNIQUES
}

\author{
A.F.H. GOETZ, B.C. GAO, CA. WESSMAN, and W.D. BOWMAN \\ Center for the Study of Earth from Space \\ Cooperative Institute for Research in Environmental Sciences \\ University of Colorado, Boulder, CO 80309-0449 \\ Ph. 303-492-5086; FAX 303-492-5070
}

\begin{abstract}
Estimation of biochemical constituents in vegetation such as lignin, cellulose, starch, sugar and protein by remote sensing methods is an important goal in ecological research. The spectral reflectances of dried leaves exhibit diagnostic absorption features which can be used to estimate the abundance of important constituents. Lignin and nitrogen concentrations have been obtained from canopies by use of imaging spectrometry and multiple linear regression techniques. The difficulty in identifying individual spectra of leaf constituents in the region beyond $1 \mu \mathrm{m}$ is that liquid water contained in the leaf dominates the spectral reflectance of leaves in this region. By use of spectrum matching techniques, originally used to quantify whole column water abundance in the atmosphere and equivalent liquid water thickness in leaves, we have been able to remove the liquid water contribution to the spectrum. The residual spectra resemble spectra for cellulose in the $1.1 \mu \mathrm{m}$ region, lignin in the $1.7 \mu \mathrm{m}$ region, and starch in the $2.0-2.3 \mu \mathrm{m}$ region. In the entire $1.0-2.3 \mu \mathrm{m}$ region each of the major constituents contributes to the spectrum. Quantitative estimates will require using unmixing techniques on the residual spectra.
\end{abstract}

\section{INTRODUCTION}

The determination of leaf chemistry from spectral remote sensing of vegetation canopies is a major goal in terrestrial ecology because it would make possible detailed study of biogeochemical processes such as productivity, decomposition and nutrient turnover rates on regional and global scales not otherwise accessible. So far, spectral reflectance measurements in the 0.4-2.5 $\mu \mathrm{m}$ region have been applied to dry ground leaf matter and the results have yielded good correlation between spectral reflectance in individual narrow (10 $\mathrm{nm}$ ) bands and leaf components such as nitrogen and lignin $[1,2]$. In fresh, green leaves the reflectance spectra beyond $1.0 \mu \mathrm{m}$ are dominated by ligand water absorption both within and without the strong 1.4 and $1.9 \mu \mathrm{m}$ absorption features. The dominant water absorption to a great extend obscures the diagnostic spectral features of the leaf biochemical components. In this paper we describe a technique to subtract the water contribution by modeling and obtain residual spectra that exhibit characteristic leaf-component spectra.

\section{BACKGROUND}

Changes in ecosystem processes such as productivity and decomposition may be expressed in the canopy foliage chemistry as a result of altered carbon allocation patterns, metabolic processes and nutrient availability. Partitioning of carbon and nutrient resources between shoots and roots is reflected in the relative concentrations of carbohydrates and 
nitrogenous compounds in leaf tissue [3,4]. Environmental stress, including change in nutrient availability, may alter resource partitioning within the plant. Increases in nitrogen supply frequently results in increased foliar nitrogen concentration $[5,6,7]$, whereas reduction in availability promotes increased secondary wall thickening and lignification $[8,9]$. Storage carbohydrates such as starch, and defensive compounds, such as polyphenols and fibers, vary predictably with resource availability and herbivory pressures $[10,11,12]$.

The quantity and organic chemical composition of litter produced by the canopy are important controlling factors in the processes of decomposition, mineralization and nitrification $[13,14,15,16]$. The recalcitrant nature of lignin modulates the rate at which litter decomposes and, hence, the release of nutrients bound in the dead tissue. Significant changes in foliar nitrogen:lignin ratios may indicate corresponding changes in decomposition rates affecting nutrient cycling and trace gas fluxes $[17,18,19]$.

The assessment of canopy biochemistry using remote sensing would provide knowledge of the spatial extent and variation of carbon/nutrient sources and sinks crucial to understanding gas exchange between vegetation and the atmosphere. Research in analytical chemistry has demonstrated that concentrations of constituents within organic mixtures can be evaluated from near infrared reflectance spectra of those mixtures $[20,21]$. Recent work in imaging spectrometry indicates that high spectral resolution data contain more information on subtle spectral features than do broad-band data. Canopy lignin concentrations were successfully estimated using NASA's Airborne Imaging Spectrometer (AIS) and were subsequently used to derive images of annual nitrogen mineralization rates in a series of Wisconsin forest ecosystems $[22,23]$.

In the AIS study, stepwise linear regression techniques were used to determine the single spectral band or bands that best correlated with measured lignin content $[22,23]$. The technique does not take advantage of the spectral shape of the lignin reflectance feature as a diagnostic tool nor the increased discrimination among other leaf components with overlapping spectral features

\section{LABORATORY MEASUREMENTS}

High spectral reflectance measurements of stacks of five fresh oak leaves were made in a Beckman 5270 spectrophotometer utilizing an integrating sphere attachment. Reflectance against a Halon standard was acquired at $5 \mathrm{~nm}$ intervals between 0.8 and 2.5 $\mu \mathrm{m}$. The specimens were weighed before and after each 45 minute run to assess dessication. The weight loss was less than $10 \%$. Spectra for fresh and dried leaves were measured.The water model spectrum was obtained by wetting a sample holder containing 100-250 $\mu \mathrm{m}$ diameter glass beads that act as inert scattering centers because of refraction between glass and water. The beads mimic the effects of leaf cell structure that contains numerous refractive index boundaries. Spectra of dry glass beads show no spectral absorption features and, therefore, the wetted-bead spectrum yields the pure water component of the leaf spectrum.

\section{SPECTRAL CURVE FITTING}

Figure 1 shows measured reflectance spectra of fresh oak leaves $\left(R_{F M}(\lambda)\right)$, dry oak leaves $\left(R_{D M}(\lambda)\right)$, and glass beads mixed with liquid water $\left(R_{W M}(\lambda)\right)$. Because the glass beads alone have no absorption bands in the 1.0-2.5 $\mu \mathrm{m}$ region, the $R_{W M}(\lambda)$ contains only liquid water absorption features centered at approximately $1.18,1.43$, and $1.92 \mu \mathrm{m}$. In order to model the observed spectra properly, the absorption and scattering properties of the sample must be known and rigorous multiple scattering calculations are required. This kind of modeling is difficult in practice. We have developed a spectral curve fitting technique to 
model reflectance spectra of fresh leaves. The procedures are as follows:

1. The approximate absorption coefficients of dry leaves $\left(K_{D}(\lambda)\right)$ and liquid water $\left(K_{W}(\lambda)\right)$ are derived from the reflectance spectra $R_{D M}(\lambda)$ and $R_{W M}(\lambda)$ according to the Eqs. $K_{D}(\lambda)=-\log \left(R_{D M}(\lambda)\right)$ and $K_{W}(\lambda)=-\log \left(R_{W M}(\lambda)\right)$. These reflectance-based absorption coefficients have already included the multiple scattering effects. They are not the same as the commonly used absorption coefficients, which are based on transmittance measurements.

2. The fresh leaf spectrum $\left(R_{F C}(\lambda)\right)$ is calculated according to

$$
R_{F C}(\lambda)=(A+B \lambda) \times \exp \left\{-\left[C_{W} K_{w}(\lambda)+C_{D} K_{D}(\lambda)\right]\right\}
$$

where $A, B, C_{w}$ and $C_{D}$ are adjustable parameters. The term $(A+B \lambda)$ represents the background level of the calculated spectrum.

3. The parameters in Eq. (1) are adjusted so that the sum of the squared differences between the observed spectrum $R_{F M}$ and the calculated spectrum $R_{F C}$ in a given spectral region is minimized. The processes of parameter adjustment and minimization are automated by incorporating our spectral calculation program into a non-linear least squares fitting program [24].

For purposes of discussion, we show the fitting procedure only for the 1.5-1.7 $\mu \mathrm{m}$ region where lignin is an important constituent. Similar results have been obtained in the $1.1 \mu \mathrm{m}$ region where cellulose is influential and in the $2.0-2.3 \mu \mathrm{m}$ region where the starch component is important.

Fig. 2 shows an example of spectral curve fitting. Both $K_{w}$ and $K_{D}$ are included in the spectral calculations, and an excellent fit between the calculated and the observed spectra is obtained. Fig. 3 shows a similar fit, but excludes $K_{D}$ in the spectral calculation (or equivalently, fixes $C_{D}$ to 0 ), and a poor fit is obtained. Fig. 3 also shows the residual spectrum, which resembles the dry leaf spectrum. Therefore, the reflectance spectra of fresh leaves in the $1.6 \mu \mathrm{m}$ region are controlled by absorptions of both the liquid water in the leaves and the dry leaf components. This contradicts conclusions of Allen et al. [25] that a sheet of liquid water can completely account for the absorption spectrum of a single leaf in the 1.4- to 2.5- $\mu \mathrm{m}$ spectral range.

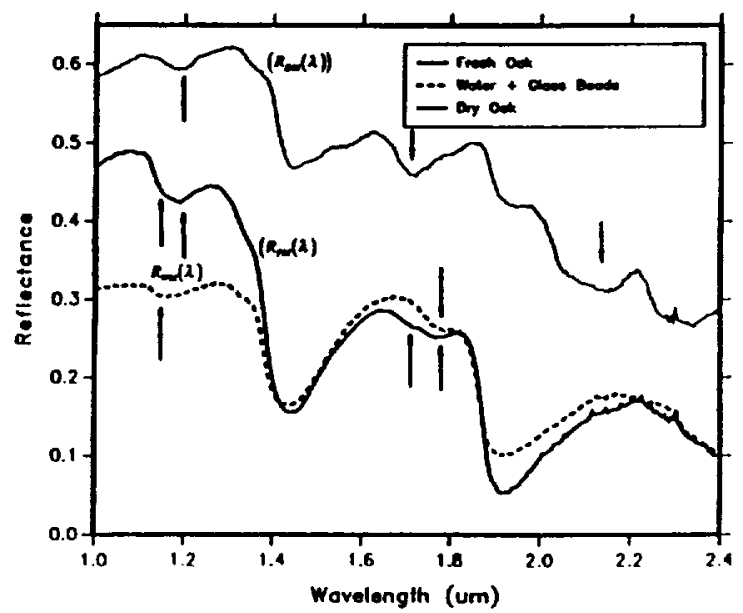

Fig. 1. Reflectance spectra of fresh and dried oak leaves and glass beads plus water. 


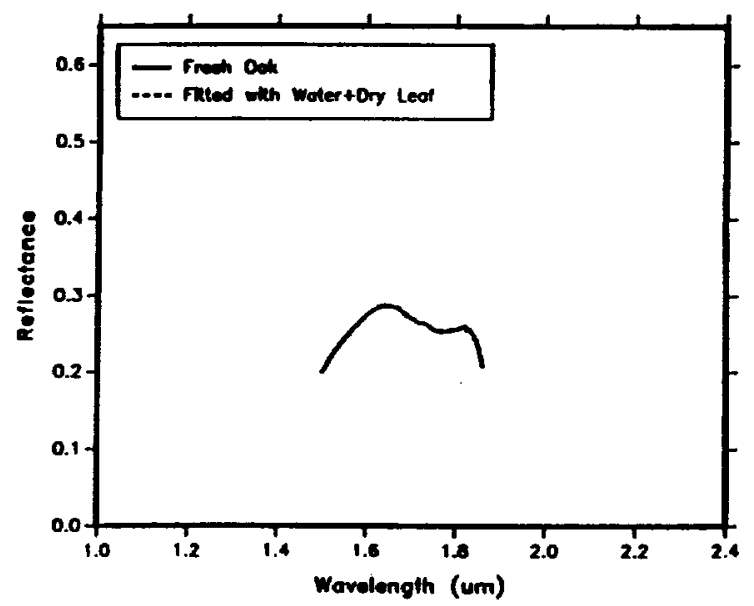

Fig. 2. Fit of the fresh leaf spectrum with the dry leaf and water spectral reflectance components.

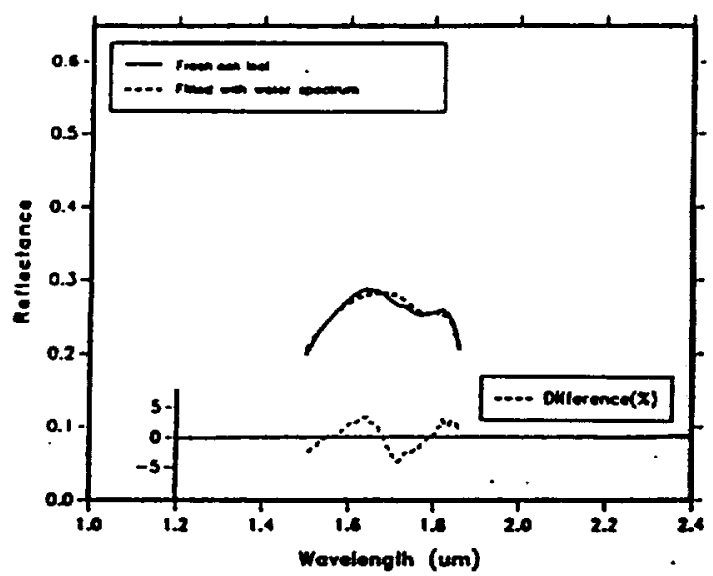

Fig. 3. Fresh leaf spectrum fitted with water spectral reflectance only. Below is the difference between the two spectra.

\section{RESUL.TS AND CONCLUSIONS}

Reflectance spectra of fresh green leaves are composed of dry leaf spectral components and water spectra. Therefore, by the proper application of model water spectra, it is possible to derive a residual spectrum that resembles the dry leaf spectrum. Further decomposition of the residual spectra into individual components should be possible using unmixing techniques [26].

The curve fitting technique will be applied to canopy spectra obtained from the Airborne Visible/Infrared Imaging Spectrometer (AVIRIS) data, and it is expected that the equivalent water thickness derived from the $0.98 \mu \mathrm{m}$ liquid water feature [27] can be used in the modeling. 


\section{REFERENCES}

[1] Card, D.H., Peterson, D.L., Matson, P.A. and Aber, J.D., Prediction of leaf chemistry by the use of visible and near-infrared reflectance spectroscopy, Rem. Sens. Environ., 26, 123-147, 1988;

[2] Peterson, D.L., Aber, J.D., Matson, P.A., Card, D.H., Swanberg, N., Wessman, C.A., and Spanner, M., Remote sensing of forest canopy and leaf biochemical contents, Rem. Sens. Environ., 24, 85-108, 1988.

[3] Lainson, R.A., Thornley, J.H.M., A model for leaf expansion in cucumber. Ann. Bot., $50,407-425,1982$.

[4] Chapin, F.S. III, Bloom, A.J., Field, C.B., Waring, R.H., Plant responses to multiple environmental factors. BioScience, 37, 49-57, 1987.

[5] Vitousek, P.M., Gosz, J.R., Grier, C.C., Melillo, J.M., Reiners, W.A., A comparative analysis of potential nitrification and nitrate mobility in forest ecosystems. Ecol. Mono., 52(2), 155-177, 1982.

[6] Binkley, D., Reid, P., Long-term increase on nitrogen availability from fertilization of Douglas-fir. Can. J. For. Res., 15(4), 723-724, 1985.

[7] Birk, E.M., Vitousek, P.M., Nitrogen availability and nitrogen use efficiency in loblolly pine stands. Ecology, 67, 69-79, 1986.

[8] Waring, R.H., McDonald, A.J.S., Larsson, S., Ericsson, T., Wiren, A., Arwidsson, E., Ericsson, A., Lohammar, T., Differences in chemical composition of plants grown at constant relative growth rates with stable mineral nutrition, Oecologia, 66, 157$160,1985$.

[9] Chapin, F.S. III, McKendrick, J.D., Johnson, D.A., Seasonal changes in carbon fractions in Alaskan tundra plants of differing growth form: implications for herbivory. J. Ecol., 74; 707-731, 1986.

[10] Mooney, H.A., Gulmon, S.L., Constraints on leaf structure and function in reference to herbivory. BioScience, 32(3), 198-206, 1982.

[11] Bryant, J.P., Chapin, F.S. III, Klein, D.R., Carbon/nutrient balance of boreal plants in relation to vertebrate herbivory. Oikos, 40, 357-368, 1983.

[12] Coley, P.D., Bryant, J.P., Chapin, F.S. III, Resource availability and plant antiherbivore defense. Science 230, 895-899, 1985.

[13] Fogel, R., Cromack, K., Effects of habitat and substrate quality on Douglas-fir litter decomposition in western Oregon. Can. J. Bot ., 55, 1632-1640, 1977.

[14] Meentemeyer, V. Macroclimate and lignin control of litter decomposition rates. Ecology, 59, 465-472, 1978.

[15] Melillo, J.M., Aber, J.D., Muratore, J.F., Nitrogen and lignin control of hardwood leaf litter decomposition dynamics. Ecology, 63(3), 621-626, 1982.

[16] Pastor, J., Post, W.M., Influence of climate, soil moisture, and succession on forest 
carbon and nitrogen cycles. Biogeochemistry , 2, 3-27, 1986.

[17] Delwiche, C.C., Bissell S., Virginia, R., Soil and other sources of nitrogen oxide. In: Nielsen, D.R., Macdonald, J.G. (eds). Nitrogen in the Environment. Academic Press, New York. pp 459-476, 1978.

[18] Vitousek, P.M., The effects of deforestation on air, soil, and water. In: Bolin, B., Cook, R.B. (eds). The Major Biogeochemical Cycles and Their Interactions. John Wiley \& Sons, New York. pp 223-245, 1983

[19] Goodroad, L.L., Keeney, D.R., Nitrous oxide emission from forest, marsh, and prairie ecosystems. J. Environ. Qual 13(3), 448-452, 1984.

[20] Wetzel, D.L., Near-infrared reflectance analysis: sleeper among spectroscopic techniques. Anal. Chem. 55, 1165A-1171A, 1983.

[21] Weyer, L.G., Near-infrared spectroscopy of organic substances. Appl. Spectr. Reo., 21(1\&2), 1-43, 1985.

[22] Wessman, C.A., Aber, J.D., Peterson, D.L., Melillo, J.M., Remote sensing of canopy chemistry and nitrogen cycling in temperate forest ecosystems. Nature 335, 154-156, 1988.

[23] Wessman, C.A., J.D. Aber, and D.L. Peterson. An evaluation of imaging spectrometry for estimating forest canopy chemistry. Int. J. Remote Sensing. 10(8), 1293-1316, 1989.

[24] Donaldson, J.R., and P.V. Tryon, Nonlinear least squares regression using STARPAC, NBS Tech. Note 1068, pp. 1-46, Nat. Bur. of Stand., Gaithersburg, Md., 1983.

[25] Allen, W.A., Gaussman, H.W., Richardson, A.J., and Thomas, J.P., Interaction of isotropic light with a compact plant leaf, J. Opt. Soc. Am., 59, 1376-1379, 1969.

[26] Boardman, J.W., 1989, Inversion of imaging spectrometry data using Singular Value Decomposition, in: Proceedings of the 1989 IGARSS, Vancouver, B.C.

[27] Gao, B-C. and A.F.H. Goetz, Column atmospheric water vapor retrievals from airborne imaging spectrometer data, J. Geophys. Res. - Atmos., 1990 (in press). 
Goetz, A.F.H., Sensing, Spectra and Scaling: What's in Store for Land Observations?, Proceedings Pecora XII Symposium, Land Information from

Space-based Systems, 55-59, Sioux Falls, South Dakota, August 24-26,1993.

Goet, A.F.H. and J. W. Boardman, Spectroscopic Measurement of Leaf Water Status, Proceedings IGARSS '95, Firenze, Italy, July 10-14.v. II, 978-980,

1995.

Gao, B.-C., A.F.H. Goetz, and J.A. Zamudio, Removing Atmospheric Effects from AVIRIS Data for Surface Reflectance Retrivals, Proc. Third Airbome May 20-24, 1991.

Gao, B.-C., K.S. Kierein-Young, A.F.H. Goetz, E.R. Westwater, B. B. Stankov, and D. Birkenheuer, Case Studies of Water Vapor and Surface Liquid Water from AVIRIS Data Measured over Denver and Death Valley, Proc. Second Annual JPL Airbome Geoscience Workshop, Jet Propulsion Laboratory, Pasadena, CA, May 20-24, 1991.

Goetz, A.F.H., B.-C. Gao, C.A. Wessman and W.D. Bowman, Estimation of Biochemical Constituents from Fresh, Green Leaves by Spectrum Matching

$\checkmark$ Techniques, Proc. International Geoscience and Remote Sensing Symposium, Remote Sensing Science for the Nineties)(IGARSS '90), v. 2, 971-974 College Park, Maryland, May 20-24, 1990.

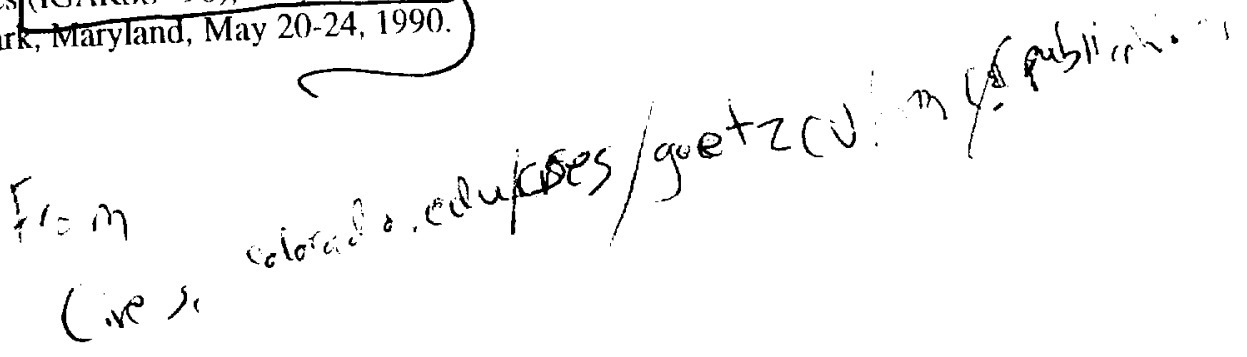


$-\longrightarrow$ 